\title{
Performance of Francophone Secondary School Leavers in English Structure and Written Expression
}

\author{
Jean-Paul Kouega ${ }^{1} \&$ Stephane Celeste Sokeng Piewo ${ }^{2}$ \\ ${ }^{1}$ Professor of English language and linguistics, Department of English, University of Yaounde I, Cameroon \\ ${ }^{2}$ Assistant Lecturer, Department of Bilingual Studies, University of Yaounde I, Cameroon \\ Correspondence: Stephane Celeste Sokeng Piewo, Assistant Lecturer, Department of Bilingual Studies, University of \\ Yaounde I, Cameroon. E-mail: sokengstephane2000@gmail.com
}

Received: February 21, 2013

Accepted: April 17, 2013

Online Published: May 2, 2013

doi:10.5430/elr.v2n1p86

URL: http://dx.doi.org/10.5430/elr.v2n1p86

\begin{abstract}
This study looks into the performance in English of Francophone learners in general, and into their mastery of structure and written expression in particular. The informants were 430 pupils who had just obtained the Baccalauréat, the certificate required for admission into tertiary education, and who came from different schools in ten regions of the country. The data were a collection of answers to a TOEFL-like test designed to check these pupils' knowledge of English structure. The analysis revealed that these pupils did not attain college level English, and the English test they took at the Baccalauréat did not seem to effectively assess knowledge of structure. To ensure that Francophones do perform well in English, there is a need to re-orient the English language syllabus and to use the time allocated to the English subject (3 hours a week for seven years) to teach them the substance of English-medium primary education content. When this is done, they would be able to take the First School Leaving Certificate examination before they complete French-medium secondary education.
\end{abstract}

Keywords: Cameroon, Official bilingualism, English in education, Testing, Francophone

\section{Introduction}

This paper reports on the first stage of an extensive work describing the proficiency in English - listening comprehension, structure and written expression, reading comprehension, and writing - of Francophones on completion of secondary education (Sokeng, 2011). The focus here is on structure and written expression i.e. major grammatical points in standard written English. Two underlying questions guided the research. These are: 1) How proficient in structure and written expression are Francophones when they leave secondary school; 2) How effective a testing tool is the English language paper in the Baccalauréat examination? The significance of this research paper lies in the fact that it has been noticed in Cameroon that the performance in English structure and written expression of secondary school leavers is very poor. This work limits itself to proficiency testing focusing on Francophone general secondary education school leavers' proficiency in English in Cameroon. The work therefore excludes all other forms of bilingualism and falls within the framework of bilingual education. It contributes to the existing body of knowledge in that it presents the current language situation in general secondary schools in terms of the evolution of bilingual education in Cameroon. This work may be of great value to the government especially the ministries in charge of Education. The problem raised in this work may push the officials of this department to revise their policies on the teaching of the second official languages in primary and secondary schools and somehow in the university. With the world becoming a global "village", with English becoming its main means of communication, with bilingual education becoming more and more popular (Oller, 1984; Wei, 2000; Hamers and Blanc, 2000; etc.) and, more importantly, with Cameroon advocating the use of both French and English by its citizens, it is projected that Francophone general secondary education school leavers would be proficient in English and would obviously be envied by Francophones in other countries like Gabon, Senegal and the like. Also, bilingualism and language testing are very important aspects in linguistics which have been discussed by many linguists (Oller, 1984; Wei, 2000, etc.). The work is divided into five sections labelled bilingualism in secondary education in Cameroon (1), English language testing in Cameroon (2), methodology (3) and data analysis and discussion (4) and lastly, proposed syllabus and assessment method (5). These are considered in turn. 


\subsection{Bilingualism in secondary education in Cameroon}

The educational system in Cameroon comprises the Anglophone subsystem and the Francophone subsystem. Both subsystems coexist but each with its specificity in assessment methods. In October 1961 when the Republic of Cameroon and the former Southern British Cameroon merged to form the Federal Republic of Cameroon, French and English were adopted as the two official languages of the country. Ever since, these two languages were introduced as a subject in the two subsystems of education: English which is the medium of instruction in Anglophone schools, was taught in Francophone schools and French which is the medium of instruction in Francophone schools, was taught in Anglophone schools. As time went on, the government made French and English compulsory subjects in all Anglophone and Francophone secondary schools respectively as well as a subject in all public examinations taken at this level. Later on these languages were introduced as from primary schools because it was observed that the proportion of secondary school students who continued their education after primary school was very limited and the performance in the second language of the students at the secondary level was very poor. Law N ${ }^{\circ}$ 98/004 of 14 April 1998, Part I, Section 2 which lays down guidelines for Education in Cameroon, states that "The State shall institute bilingualism at all levels of education as a factor of national unity and integration".

To foster the practice of bilingualism, the State created the first bilingual school in 1965 in Man O War Bay. The students were requested to use both languages in class. No distinction was made; Francophones and Anglophones were attending the same classes. Half of the classes were in French and the other half in English. This is no more the case. Now, French is taught to Anglophones and English to Francophones in all secondary schools as a second language.

The objectives of bilingual schools as stated in the "Final Report on the Reinforcement of Bilingualism in the Cameroon Education System" are as follows (MINEDUC 2000:11):

a) to consolidate national unity and integration through mutual self-respect by understanding each other's cultural background. Cultural background here should mean, Anglophone or Francophone background;

b) to provide opportunities for Cameroonian children irrespective of their ancestral villages or places of birth to evolve educationally in the cultural system of their parents' choice;

c) to recreate, as it were, a microcosm of the Cameroonian society, in which students would live together and interact and thereby, hopefully breaking down some of the walls of prejudice and ignorance about each other's language group;

d) to produce highly bilingual individuals who would be models to other Cameroonians;

e) to produce a core of highly bilingual citizens to prop up the bilingual machinery of the state in areas such as education translation and the civil service;

f) to eventually produce a core of cadres who would be suited for eventual training as translators and interpreters.

Recently, decision number 1141/B1/1464/MINEDUC/IGE/BIL of 28th October 2002 instituted a National Day of Bilingualism in all public and private schools in Cameroon with effect from the 2002-2003 school year, this with the aim of fostering bilingualism in secondary education. A day is chosen in the week by the school authority and called "Bilingualism Day" for French-speaking secondary schools and Journée du Bilinguisme for English-speaking schools. On this day, all students and administrative staff are expected to communicate in their second official language during specific moments of the day (example: long breaks, morning assembly...). In addition to this day, decision number B1/1464/MINEDUC/IGE/PGP/BIL aims at revamping practical bilingualism in secondary schools with the creation of "English Clubs" for French-speaking students, "Clubs de Français" for English-speaking students, the singing of the national anthem in both official languages and the awarding of prizes to the best bilingual students in each class.

The "Final Report on the Reinforcement of Bilingualism in the Cameroon Education System" (MINEDUC, 2000: 21-2) outlines a number of problems that hinder bilingualism in bilingual schools:

a) There is usually a general lack of teachers in some of the remote bilingual colleges;

b) All the so-called bilingual schools are in reality, two schools juxtaposed;

c) Because of the reasons above, many bilingual schools are empty shells that give parents and students a false sense of what they are;

d) It is the duty and responsibility of all colleges and high schools to promote bilingualism; 
e) Both second official languages are not tested at the end of course examinations in the primary schools. This has a negative wash-back effect on teaching and learning;

f) There are no single compound bilingual primary schools with one head teacher. In all, there are a handful of primary schools which are called bilingual primary schools particularly in the French-speaking regions. They are bilingual only in name;

g) Parents and teachers found the elitist system too demanding on students;

h) The Molyko experiment was too expensive since it required that parents should buy two sets of books;

i) It was not cost effective as too much money and energy and staff was spent on a minority of elitist group of students;

j) The experiment was unnecessary since bilingual secondary school students could be produced in normal colleges and high schools;

k) The whole exercise was a grope in the dark as there was no long term vision or policy on bilingual schools vis-à-vis other schools.

What is assessed in this work is the outcome of English taught as a subject to Francophone learners for a period of seven years.

\section{English language testing in Cameroon}

This section reviews works that have focused on the testing of any aspect of the English of Francophones at the secondary level. Then it examines the English language paper in the Baccalauréat examinations. The readily available works on English language testing were produced by Eyenga (2007) and Mbia (2007). Eyenga (2007) took up the testing of the speaking skill in the teaching of English as a Foreign Language (EFL) in Cameroon secondary schools, a case study of Government Bilingual Practising High School Yaounde focusing on 'Troisième Anglais Renforcé 1 (3è Are1) and 'Terminale A1 and A2' (Tle A1 and Tle A2) students. It was found that oral skills were hardly integrated into the testing of Francophone Learners of English (FLE)'s competence in secondary schools. Furthermore, whenever this aspect is tested, the test is limited to a set of sounds presented to the learners who are simply asked to select the odd sound among the other sounds. She tries to focus attention on the testing of the oral skills in Cameroonian secondary schools. The investigations reveal that FLE especially those in Tle A2 and $3 \dot{e}$ Are1 in GBPHS Yaounde are tested regularly in writing and reading and rarely in speaking. The number of lessons to be taught does not allow EFL teachers to spend much time on testing speaking. Speaking is said not to be tested because of the size of the classes and the lack of adequate testing materials. Poor mastery of methods and techniques for testing the speaking skill also seemed to be a real problem. On the basis of these findings, a number of recommendations were made:

- teachers should read about speaking tests, as this would lead to a better understanding of this form of testing;

- they should set their tests in groups in order to avoid some inherent weaknesses;

- they should always test speaking alongside listening, reading, grammar and vocabulary

- and finally, school inspectors should endeavour to organise seminars and workshops on testing speaking in examinations.

Mbia (2007) evaluated the English language test administered to students at the Baccalauréat A4 official examination and their performance. He focused on the reading and essay sections. In Reading comprehension, certain texts deal with out-of-date issues, making the understanding of the text difficult for the students; for example the reading comprehension passage of the 2005 Baccalauréat A4 session was on the catastrophe of Lake Nyos. The title was 'Lake of Death'. This catastrophe happened in 1986 about twenty years before, and many students at that time were not yet born. Besides, some reading texts were far-fetched or not relevant to students' local interest. For example, the comprehension section of the 2002 Baccalauréat A' session was about the story of a Japanese child whose name was Yuki Sato. The title of the text was 'We have aside 100 million Yen to make your dream, come true'. The story was full of Japanese names which were culture-bound and this did not enable students to understand the text very well since a good number of these words were not easy to read. He concluded that a text that is related to a current Cameroonian event would be appealing to the students and they would understand it without any difficulty.

In Essay Writing, the topics were found not to conform to the environment in which the students lived. The 2005 Baccalauréat A4 last essay topic was on the importance of taking care of the environment: 'Imagine that today is 
Earth Day. Write an article in your school journal to show the importance of taking care of the environment.' It was clear that only students in urban areas could treat this topic since the media in those places discuss such issues as the protection of the environment. On the contrary, students in rural areas were disfavoured since most of them did not have access to the media because of the lack of electricity or financial means. Another major finding is that the Baccalauréat A4 examination does not take into consideration the prescriptions of the syllabus. First, the writing test turns around simple narrative, argumentative, descriptive essays and letter writing whereas the syllabus prescribes other techniques such as contracting texts, writing poems, etc. One last finding is that the reading comprehension section always comprises two parts i.e. a passage and a series of questions, whereas the syllabus prescribes the interpretation of charts, tables, graphs and other non-linguistic material in texts.

To check Mbia (2007)'s findings, the researchers looked into the English paper at the 2008 Baccalauréat examination in Cameroon. The paper comprised four sections, lettered A to D. Section A (25\%) included two grammar exercises and one phonology exercise. The instruction and the first items of each exercise are reproduced below:

Section A

1. Complete the following sentences by putting the items in the brackets in their correct forms.

a) It's high time you....................................... (to buy) your own calculator.

2. Complete the sentences with the most appropriate words chosen from the brackets.

a) Bola is the silliest boy I've .............................met. (always, never, ever)

3 . Write the word in which the underlined letters are pronounced differently.

a) Word, corn, sword, sort, storm.

The second section (25\%) which was labelled vocabulary, included two exercises; the instructions and the first item of each exercise are reproduced here:

\section{Section B}

1. Complete the sentences with the most appropriate prepositions:

a) Last year, Jack was nearly convicted .................................murder. He was instead charged..................theft. The other cases................him were dismissed.

2. Build compound words by matching the words in column A to those in column B, write in the spaces provided.

Column AColumn BYour answer

Killer Penalty

The third section (25\%) was labelled Reading comprehension. It comprised a text extracted from a book or article entitled "Beyond the hidden pain of abortion" by Patricia A. Bigliardi. The instructions were followed by a sequence of six questions.

Section C. Reading comprehension

Read the following passage and answer the questions below it, using your own words as far as you can.

1 . Who are the two main characters of the passage?

The fourth section (25\%) was an essay and the candidates were expected to choose one of three topics.

Section D. Essay

Write a composition of about 250-300 words on ONE of three topics.

1. Abortions: causes and setbacks.

It can be concluded that the English paper in the Baccalauréat examination assesses grammar, vocabulary, reading comprehension and essay writing and it does not measure listening and speaking. This work will now subject these same Baccalauréat holders to a test that measures structure and written expression, which can be likened to what they know as grammar and vocabulary. 


\section{Methodology}

This section describes the informants for this study (3.1), the material used and its administration (3.2), and the validation of the designed test (3.3).

\subsection{The informants}

The informants were 430 pupils who had just obtained their Baccalauréat; they did secondary education in the ten regions of the country and had in common the fact that they were the top pupils that year, as their classmates had failed. It should be pointed that thanks to internal migration, many pupils who go to school in a given locality do not necessarily originate from that locality. These informants were of both sexes, were aged 16-23. Some were science-oriented while others were arts-oriented. The actual number drawn from each region was proportional to the number of candidates who obtained this certificate in that region. In all, there were 430 informants, distributed as shown in Table 1.

Table 1. Details on the informants (number, sex and fields of study)

\begin{tabular}{l|l|l|l|l|l}
\hline \multirow{2}{*}{ Region } & \multirow{2}{*}{ Number } & \multicolumn{2}{l|}{ Sex } & \multicolumn{2}{l}{ Type of Baccalauréat } \\
\cline { 3 - 6 } & & $\mathrm{F}$ & $\mathrm{M}$ & Arts & Science \\
\hline Adamawa & 10 & 3 & 7 & 7 & 3 \\
Centre & 140 & 78 & 62 & 57 & 83 \\
East & 20 & 9 & 11 & 13 & 7 \\
Far north & 20 & 5 & 15 & 16 & 4 \\
Littoral & 100 & 49 & 51 & 36 & 64 \\
North & 20 & 8 & 12 & 8 & 12 \\
Northwest & 10 & 7 & 3 & 5 & 5 \\
South & 20 & 7 & 13 & 9 & 11 \\
Southwest & 10 & 6 & 4 & 8 & 2 \\
West & 80 & 27 & 53 & 27 & 53 \\
Total & 430 & $199(46.2 \%)$ & $231(53.7 \%)$ & $186(43.2 \%)$ & $244(56.7 \%)$ \\
\hline
\end{tabular}

\subsection{The material}

The data collected for this study were the answer sheets of a TOEFL-like test designed with the informants' background in mind. Francophone pupils in Cameroon are part of the international community and they should therefore be subjected to the types of tests that pupils of comparable levels of education in the world take. The Test of English as a Foreign Language (TOEFL) evaluates the potential success of an individual in using and understanding English at a college level (http://en.wikipedia.org/wiki/TOEFL). There exist 3 types of TOEFL tests namely the Computer-Based Test (CBT), the Internet-based Test (iBT), and the Paper-Based Test. The latter type was adopted for this study, as the other two types require the use of a computer. It consists of the following four sections i.e. listening comprehension done in 40 minutes, vocabulary and reading comprehension done in 55 minutes, test of written English done in 30 minutes, and structure and written expression done in 25 minutes. The test designed for this study was limited to the structure and written expression component of the TOEFL, as this component can readily be likened to the Grammar and vocabulary exercises the informants are used to (see sample Baccalauréat examination paper in Appendix 1).

The structure and written expression component of a TOEFL test comprises two parts and a total of 40 questions which aim to measure the test taker's ability to recognize language that is appropriate for standard written English. Below are reproduced the directions and the first items of each part of the test designed for this study.

Part A

Directions: Questions 1-15 are incomplete sentences. Beneath each sentence you will see four words or phrases, marked (A), (B), (C), and (D). Choose the one word or phrase that best completes the sentence.

1. To answer accurately is more important than.
(A) a quick finish
(B) to finish quickly
(C) finishing quickly
(D) you finish quickly 
Part B

Directions: In questions 16-40, each sentence has four underlined words or phrases. The four underlined parts of the sentence are marked (A), (B), (C), and (D). Circle the one underlined word or phrase that must be changed in order for the sentence to be correct.

16. The project $\underline{\boldsymbol{w h o}}$ will be managed in segments is expected to cost $\underline{\mathrm{CFA} 1,745,200 .}$.
(A)
(B)
(C)
(D)

The full test is reproduced in Appendix 2, together with the answer sheet filled by the informants. Indexical information on the informants (the region where they studied, their age range, their sex and the specific class they attended) was required. For reasons of availability, the test was administered continuously till the targeted number of informants for each region was attained.

\subsection{Validation of the designed test}

To check the validity of this test, the researchers administered it to pupils who have followed the English-medium of education. A total of 45 Form II pupils drawn from Yaounde (a Francophone town) and Limbe (an Anglophone town) were subjected to this test. To facilitate comparison, the results were grouped into three categories, labelled 1 to 3 :

- Category 1: scores between 0-19 out of 40 (less than $50 \%$ )

- Category 2: scores between 20-29 out of 40 (between $50 \%$ and $75 \%$ )

- Category 3: scores between 30-40 out of 40 (above 75\%)

As no difference was observed in the performance of Limbe and Yaounde pupils, the results are lumped together in Table 2:

Table 2. Overall scores in Structure of Form II informants

\begin{tabular}{|l|l|l|l|l|}
\hline Test & Category 1 (0-19) & Category 2 (20-29) & Category 3 (30-40) & Total \\
\hline Structure & $9(20 \%)$ & $22(48.9 \%)$ & $14(31.1 \%)$ & $45(99.9 \%)$ \\
\cline { 3 - 5 } & & & $36(80 \%)$ & \\
\hline
\end{tabular}

The detailed score of each of the 45 informants in the 40 questions is presented in Table 3.

Table 3. Detailed scores in Structure of Form II students

\begin{tabular}{|c|c|c|c|c|c|}
\hline \multicolumn{2}{|l|}{ Category 1} & \multicolumn{2}{|l|}{ Category 2} & \multicolumn{2}{|l|}{ Category 3} \\
\hline Score out of 40 & $\begin{array}{l}\text { Number of } \\
\text { respondents }\end{array}$ & Score out of 40 & $\begin{array}{l}\text { Number of } \\
\text { respondents }\end{array}$ & Score out of 40 & $\begin{array}{l}\text { Number of } \\
\text { respondents }\end{array}$ \\
\hline 0 & & 20 & 11 & 30 & 8 \\
\hline 1 & & 21 & & 31 & 3 \\
\hline 2 & & 22 & & 32 & \\
\hline 3 & & 23 & 1 & 33 & 1 \\
\hline 4 & & 24 & 4 & 34 & 2 \\
\hline 5 & & 25 & 1 & 35 & \\
\hline 6 & 1 & 26 & 1 & 36 & \\
\hline 7 & & 27 & 2 & 37 & \\
\hline 8 & & 28 & & 38 & \\
\hline 9 & & 29 & 2 & 39 & \\
\hline 10 & & & & 40 & \\
\hline 11 & & & & & \\
\hline 12 & 2 & & & & \\
\hline 13 & & & & & \\
\hline 14 & & & & & \\
\hline 15 & & & & & \\
\hline 16 & & & & & \\
\hline 17 & 2 & & & & \\
\hline 18 & 1 & & & & \\
\hline 19 & 3 & & & & \\
\hline Total & $9(20 \%)$ & & $22(48.9 \%)$ & & $14(31.1 \%)$ \\
\hline Total & $9(20 \%)$ & & & $36(80 \%)$ & \\
\hline
\end{tabular}


As this table shows, $20 \%$ of the 45 informants failed in the test while $80 \%$ passed in it, with $31.1 \%$ of the 45 scoring over $75 \%$. It is assumed that Baccalauréat holders to be tested would attain a similar performance, as they had studied English as a subject throughout their seven years of secondary education.

\section{Analysis and discussion}

The analysis is divided into ten sections, each taking up the pupils who graduated from schools in the same region.

4.1 Adamawa region

The ten scripts of informants who obtained their Baccalauréat in the Adamawa region were marked and the following scores were recorded.

Table 4. Scores in Structure of students who were tested who graduated from schools in the Adamawa region

\begin{tabular}{|c|c|c|c|c|}
\hline $\begin{array}{ll}\text { Test } & \text { Score }\end{array}$ & Category $1 \quad(0-19)$ & Category 2 (20-29) & Category 3 (30-40) & Total \\
\hline \multirow[t]{2}{*}{ Structure } & \multirow[t]{2}{*}{$7(70 \%)$} & $3(30 \%)$ & $0(0 \%)$ & \multirow[t]{2}{*}{$10(100 \%)$} \\
\hline & & \multicolumn{2}{|c|}{$3(30 \%)$} & \\
\hline
\end{tabular}

As this results show, $70 \%$ of 10 students who were tested fell in Category 1 while only $30 \%$ fell in Category 2 and none in Category 3.

The detailed score of each of the 10 informants in the 40 questions is presented in Table 5.

Table 5. Detailed scores in Structure of students who were tested from schools in the Adamawa region

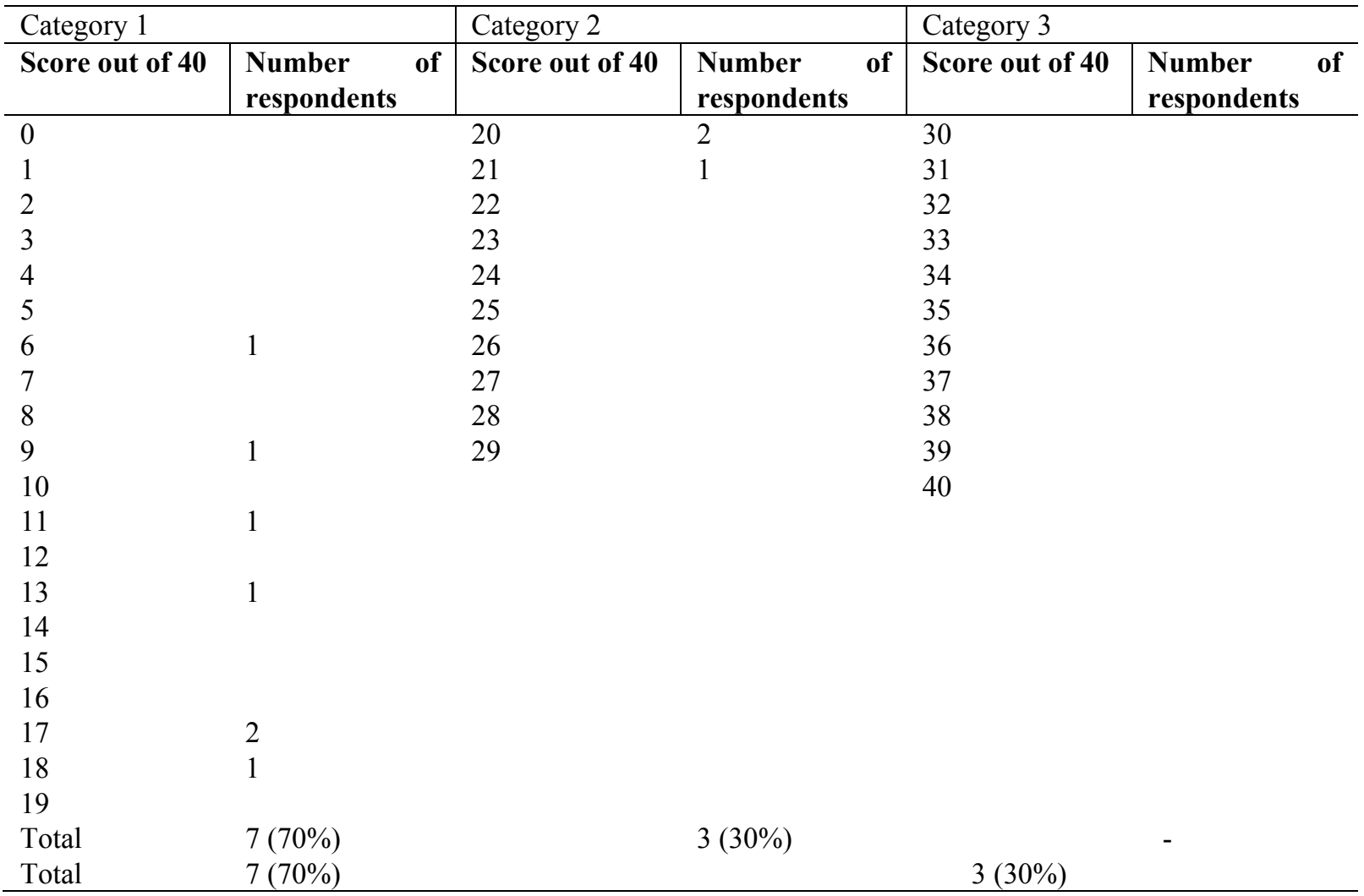

A close look at the informants' answer sheets revealed that they had a serious problem using tenses in English, notably the simple past and the past perfect tenses. Almost all the informants got questions 8 and 9 wrong:

Question 8

Another sub-theme discussed last year

..to do with management.
(A) was
(B) is
(C) have
(D) had 
In this example, the verb to be used is the verb 'to have' which restricts the correct answers to (C) or (D). The first two answers (A) and (B) are the verb 'to be' in the past and in the present tense respectively. The respondent could be guided by the verb 'to discuss' used in the past or by the phrase 'last year' denoting past time. Thus, answer (C) cannot be chosen because it is in the present tense, meaning that if the respondent chooses this answer, the action is still being done, which is not the case in the sentence. The correct answer is (D).

Question 9

The 2008 Africa Nation's cup in Ghana.
(A) is held
(B) was held
(C) was hold
(D) has been hold

Here, the verb to be used is 'was held' (B).

\subsection{Centre region}

The 140 informants who had obtained their Baccalauréat in the Centre region got the scores outlined in Table 6.

Table 6. Scores in Structure of students who were tested who graduated from schools in the Centre region

\begin{tabular}{|c|c|c|c|c|}
\hline $\mathrm{C}_{\text {Test }}$ Score & Category 1 (0-19) & Category 2 (20-29) & Category 3 (30-40) & Total \\
\hline \multirow[t]{2}{*}{ Structure } & \multirow[t]{2}{*}{$80(57.1 \%)$} & $46(32.8 \%)$ & $14(10 \%)$ & \multirow[t]{2}{*}{$140(99.9 \%)$} \\
\hline & & \multicolumn{2}{|c|}{$60(42.8 \%)$} & \\
\hline
\end{tabular}

It was found $57.1 \%$ of 140 informants fell in Category 1 . Their major difficulty was in the area of Agreement or Concord, as they all failed Questions 16 and. 32

Question 16

The project who will be managed in segments is expected to cost $\underline{\text { CFA } 1,745,200}$.
(A)
(B)
(C)
(D)

The correct answer is (A). The relative pronoun 'who' is used for people not objects or abstract realities. Normally, this sentence should read: 'The project which will be managed in segments is expected to cost CFA 1, 745, 200'.

Question 32

It is a long time I has not received any letter; I only receive and send electronic mails.
(A)
(B)
(C)
(D)

Many respondents circled answer (A) and (C) but the correct answer is (B) because the subject of the verb 'to have' here is ' $I$ '.

\subsection{East region}

The performance of the 20 informants tested is presented in Table 7.

Table 7. Scores in Structure of students who were tested who graduated from schools in the East region

\begin{tabular}{|c|c|c|c|c|}
\hline 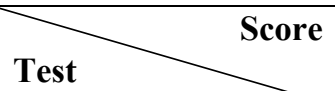 & Category $1 \quad(0-19)$ & Category 2 (20-29) & Category $3(30-40)$ & Total \\
\hline Structure & $18(90 \%)$ & $2(10 \%)$ & $-(0 \%)$ & $\begin{array}{l}20 \\
(100 \%)\end{array}$ \\
\hline
\end{tabular}

As these figures show, the bulk of the students who were tested $90 \%$ of 20 fell in Category 1. One basic exercise they all got wrong is Question 17. 
Question 17

The main characters are clearly delineated between the first chapter of the book.
A)
(B)
(C)
(D)

The correct answer here is (D) which is to be replaced by the preposition "in".

\subsection{Far North region}

Below are presented the results of the 20 informants who were tested.

Table 8. Scores in Structure in the Far North region

\begin{tabular}{|c|c|c|c|c|}
\hline Test $\quad$ Score & Category $1 \quad(0-19)$ & $\begin{array}{ll}\text { Category } & 2 \\
(20-29) & \end{array}$ & Category $3 \quad(30-40)$ & Total \\
\hline \multirow{2}{*}{ Structure } & \multirow[t]{2}{*}{$18(90 \%)$} & $2(10 \%)$ & $0(0 \%)$ & \multirow{2}{*}{$20(100 \%)$} \\
\hline & & \multicolumn{2}{|c|}{$2(10 \%)$} & \\
\hline
\end{tabular}

These informants seem not to know how to use a number of sentence elements including prepositional verbs.

Question 5

Poverty is often accompanied appetite.
(A) by
(B) with
(C) of
(D) in

The informants chose (C) which is not correct. They surely translated from the French expression 'accompagné de' but the correct expression in English in this example is ' to be accompanied by'. So, the correct answer is (A). It is the same for question 7 :

Question 7

Together let's fight

AIDS.
(A) for
(B) against
(C) any
(D) again

Here, the correct answer is (B) and not (A) as most of the respondents chose. To 'fight for' means to 'agree with' which is not the intended meaning here.

\subsection{Littoral region}

A total of 100 informants who had schooled in this region took the test and their scores are reported in Table 9.

Table 9. Scores in Structure of students who were tested who graduated from schools in the Littoral region

\begin{tabular}{|c|c|c|c|c|}
\hline $\begin{array}{ll}\text { Test } & \text { Score }\end{array}$ & Category $1 \quad(0-19)$ & Category 2 (20-29) & Category 3 (30-40) & Total \\
\hline \multirow[t]{2}{*}{ Structure } & \multirow[t]{2}{*}{$53(53 \%)$} & $37(37 \%)$ & $10(10 \%)$ & \multirow[t]{2}{*}{$100(100 \%)$} \\
\hline & & \multicolumn{2}{|c|}{$47(47 \%)$} & \\
\hline
\end{tabular}

The grammatical rule related to comparative construction is not clear to students as we can see in question 6 .

Question 6

The greater the demand. the price.
(A) the high
(B) the higher
(C) high
(D) higher 
In this sentence, the phrase 'The greater' must agree with the second, so the correct answer is (B); the sentence reads 'The greater the demand, the higher the price.'

Question 12

It is never to take the AIDS test.
(A) early
(B) earlier
(C) too early
(D) too earlier

In this example, the correct answer is (C). Most of the informants chose (D) which is not correct.

4.6 North region

20 informants were randomly selected for this analysis and their scores are displayed in Table 10:

Table 10. Scores in Structure of students who were tested who graduated from schools in the North region

\begin{tabular}{|c|c|c|c|c|}
\hline $\begin{array}{l}\text { Test } \\
\text { Score }\end{array}$ & $\begin{array}{ll}\text { Category } 1 & (0-19)\end{array}$ & Category 2 (20-29) & Category 3 (30-40) & Total \\
\hline \multirow[t]{2}{*}{ Structure } & \multirow[t]{2}{*}{$17(85 \%)$} & $3(15 \%)$ & $0(0 \%)$ & \multirow[t]{2}{*}{$20(100 \%)$} \\
\hline & & \multicolumn{2}{|c|}{$3(15 \%)$} & \\
\hline
\end{tabular}

Informants who graduated from the North region appeared to have problems with plurality and collective nouns in English as it is the case in the following examples:

Question 23

You can have more job opportunity if you are bilingual.
(A)
(B)
(C)
(D)

When a noun ends in $-y$ preceded by a consonant, the plural is formed by changing the $-y$ to $i$ and adding $-e s$. The correct answer is (C). The correct sentence is: You can have more job opportunities if you are bilingual.

Question 33

If you need more informations, please contact our office.
(A)
(B)
(C)
(D)

Collective nouns name a group of people or things. They do not change in the plural; it is the case with the word information as in this example. The correct answer is (B).

4.7 Northwest region

The ten informants selected obtained the following scores:

Table 12. Scores in Structure of students who were tested who graduated from schools in the Northwest region

\begin{tabular}{|c|c|c|c|c|}
\hline Test & $\begin{array}{ll}\text { Category } & 1 \\
(0-19) & \\
\end{array}$ & Category 2 (20-29) & $\begin{array}{ll}\text { Category } & 3 \\
(30-40) & \\
\end{array}$ & Total \\
\hline \multirow[t]{2}{*}{ Structure } & \multirow[t]{2}{*}{$3(30 \%)$} & $5(50 \%)$ & $2(20 \%)$ & \multirow{2}{*}{$\begin{array}{l}10 \\
(100 \%)\end{array}$} \\
\hline & & \multicolumn{2}{|c|}{$7(70 \%)$} & \\
\hline
\end{tabular}

These informants are better off as they followed French-medium education in one of the Anglophone regions of Cameroon. They however had problems with the formation of the plural of collective nouns in English. Collective nouns designate a group of people, animals or objects, as in Question 25.

Question 25

Political leaders often flatter peoples because they want to be elected.
(A)
(B)
(C)
(D)

Here the word that must be changed in order for the sentence to be correct is peoples. So the correct answer is (C). 


\subsection{South region}

The 20 informants selected had the following scores:

Table 12. Scores in Structure of students who were tested who graduated from schools in the South region

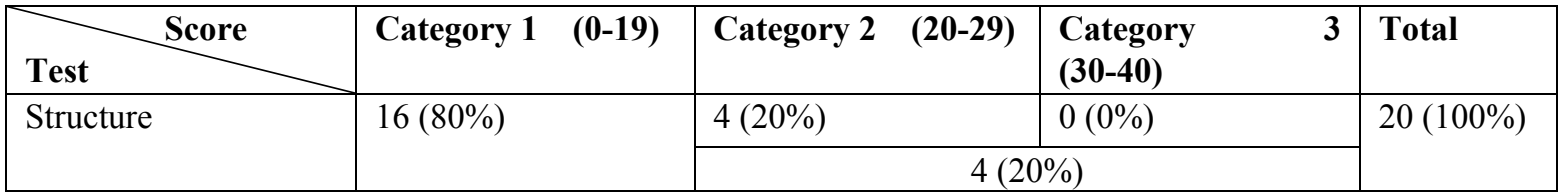

As Table 12 shows, $80 \%$ of the informants fell in Category 1 and $20 \%$ fell in Category 2.

Informants also seemed to have some trouble with lots of features including agreement. A pronoun agrees with its antecedent in number, gender and person. In this case there is agreement in number. If the antecedent of a pronoun is singular, a singular pronoun is required. If the antecedent is plural, a plural pronoun is required, as in this example:

Question 38

The more important or powerful a person is, the more difficult it is for them when he

(C)

(D)

loses his importance or power.

The correct answer is (D), them is the word which has to be changed for the sentence to be correct: The more important or powerful a person is, the more difficult it is for him when he loses his importance or power.

\subsection{Southwest region}

Of the 10 informants who took the test, $80 \%$ fell in Categories 2 and 3. In fact they were pupils attending French-medium schools in an Anglophone region.

Table 13. Scores in Structure of students who were tested who graduated from schools in the Southwest region

\begin{tabular}{|c|c|c|c|c|}
\hline Test Score & Category 1 (0-19) & Category 2 (20-29) & $\begin{array}{ll}\text { Category } & 3 \\
(30-40) & \end{array}$ & Total \\
\hline \multirow[t]{2}{*}{ Structure } & \multirow[t]{2}{*}{$2(20 \%)$} & $5(50 \%)$ & $3(30 \%)$ & \multirow[t]{2}{*}{$10(100 \%)$} \\
\hline & & \multicolumn{2}{|c|}{$8(80 \%)$} & \\
\hline
\end{tabular}

Some of them however had difficulties with tenses as it is the case in the example below:

Question 14

Many young Africans respect immigration policies and end up being killed.
(A) do
(B) do not
(C) did not
(D) will not

Many respondents chose answers (C) and (D), which are wrong. The correct answer is (B).

\subsection{West region}

The 80 students who were tested performed as follows.

Table 14. Scores in Structure of students who were tested who graduated from schools in the West region

\begin{tabular}{|c|c|c|c|c|}
\hline $\begin{array}{ll}\text { Test } & \text { Score }\end{array}$ & Category $1 \quad(0-19)$ & Category 2 (20-29) & $\begin{array}{ll}\text { Category } & 3 \\
(30-40) & \end{array}$ & Total \\
\hline \multirow[t]{2}{*}{ Number } & \multirow[t]{2}{*}{$60(75 \%)$} & $14(17.5 \%)$ & $6(7.5 \%)$ & \multirow{2}{*}{$\begin{array}{l}80 \\
(100 \%)\end{array}$} \\
\hline & & \multicolumn{2}{|c|}{$20(25 \%)$} & \\
\hline
\end{tabular}

Their poor performance was due to the poor mastery of a number of features including plurality, as Question 35 shows: 
Question 35

These is a warning from the Ministry of Public Health: illegal drugs can kill!
(A)
(B)
(C)
(D)

The correct answer is (A).

4.11 A comparison of respondents' proficiency in Structure in the ten regions

The respondents' proficiency in Structure in the ten regions is displayed in Table 15, where Categories 2 and 3 are merged.

Table 15. Proficiency in Structure in the ten regions

\begin{tabular}{l|l|l|l}
\hline \multicolumn{1}{c}{ Region } & $\begin{array}{l}\text { Score } \\
\text { Category 1 } \\
(\mathbf{0 - 1 9})\end{array}$ & $\begin{array}{l}\text { Categories 2 and 3 } \\
(\mathbf{2 0 - 4 0 )}\end{array}$ & Total \\
\hline Adamawa & $7(70 \%)$ & $3(30 \%)$ & $10(100 \%)$ \\
Centre & $80(57.1 \%)$ & $60(42.8 \%)$ & $140(100 \%)$ \\
East & $18(90 \%)$ & $2(10 \%)$ & $20(100 \%)$ \\
Far North & $18(90 \%)$ & $2(10 \%)$ & $20(100 \%)$ \\
Littoral & $53(53 \%)$ & $47(47 \%)$ & $100(100 \%)$ \\
North & $17(85 \%)$ & $3(15 \%)$ & $20(100 \%)$ \\
Northwest & $3(30 \%)$ & $7(70 \%)$ & $10(100 \%)$ \\
South & $16(80 \%)$ & $4(20 \%)$ & $10(100 \%)$ \\
Southwest & $2(20 \%)$ & $8(80 \%)$ & $80(100 \%)$ \\
West & $60(75 \%)$ & $20(25 \%)$ & $\mathbf{4 3 0}(\mathbf{9 9 . 9 \% )}$ \\
Total & $\mathbf{2 7 4 ( 6 3 . 7 \% )}$ & $\mathbf{1 5 6}(\mathbf{3 6 . 2 \% )}$ & . \\
\hline
\end{tabular}

A close look at Table 15 reveals that 274 informants out of 430 (63.7\%) fell in Category 1, while $36.2 \%$ fell in Categories 2 and 3 .

Table 16. Proficiency ranking in Structure in the ten regions

\begin{tabular}{lllll}
\hline $\mathbf{n}=\mathbf{4 3 0}$ & \multicolumn{1}{c}{ Total } & Rank \\
\hline $\begin{array}{l}\text { Score } \\
\text { Region }\end{array}$ & $\begin{array}{c}\text { Category 1 } \\
(\mathbf{0 - 1 9 )}\end{array}$ & $\begin{array}{l}\text { Categories 2 and 3 } \\
\mathbf{( 2 0 - 4 0 )}\end{array}$ & & \\
Adamawa & $7(70 \%)$ & $3(30 \%)$ & $10(100 \%)$ & $5^{\text {th }}$ \\
Centre & $80(57.1 \%)$ & $60(42.8 \%)$ & $140(99.9 \%)$ & $4^{\text {th }}$ \\
East & $18(90 \%)$ & $2(10 \%)$ & $20(100 \%)$ & $10^{\text {th }}$ \\
Far North & $18(90 \%)$ & $2(10 \%)$ & $20(100 \%)$ & $10^{\text {th }}$ \\
Littoral & $53(53 \%)$ & $47(47 \%)$ & $100(100 \%)$ & $3^{\text {rd }}$ \\
North & $17(85 \%)$ & $3(15 \%)$ & $20(100 \%)$ & $8^{\text {th }}$ \\
Northwest & $3(30 \%)$ & $7(70 \%)$ & $10(100 \%)$ & $2^{\text {nd }}$ \\
South & $16(80 \%)$ & $4(20 \%)$ & $20(100 \%)$ & $7^{\text {th }}$ \\
Southwest & $2(20 \%)$ & $8(80 \%)$ & $10(100 \%)$ & $1^{\text {st }}$ \\
West & $60(75 \%)$ & $20(25 \%)$ & $80(100 \%)$ & $6^{\text {th }}$
\end{tabular}

As Table 16 shows, pupils from the Southwest and Northwest, which are the Anglophone regions of the country, occupy the first and second position in Structure and written expression. Among the eight purely Francophone regions, the Littoral and the Centre occupy the first and second position. 
Table 17. Proficiency ranking in Structure in the eight Francophone regions

\begin{tabular}{|c|c|c|c|c|}
\hline Region & $\begin{array}{ll}\text { Category } & 1 \\
(0-19) & \\
\end{array}$ & 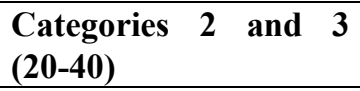 & Total $^{(\mathrm{n}=430)}$ & Rank \\
\hline Littoral & $53(53 \%)$ & $47(47 \%)$ & $100(100 \%)$ & $1^{\mathrm{st}}$ \\
\hline Centre & $80(57.1 \%)$ & $60(42.8 \%)$ & $140(99.9 \%)$ & $2^{\text {nd }}$ \\
\hline Adamawa & $7(70 \%)$ & $3(30 \%)$ & $10(100 \%)$ & $3^{\text {rd }}$ \\
\hline South & $16(80 \%)$ & $4(20 \%)$ & $20(100 \%)$ & $4^{\text {th }}$ \\
\hline West & $60(75 \%)$ & $20(25 \%)$ & $80(100 \%)$ & $5^{\text {th }}$ \\
\hline North & $17(85 \%)$ & $3(15 \%)$ & $20(100 \%)$ & $6^{\text {th }}$ \\
\hline East & $18(90 \%)$ & $2(10 \%)$ & $20(100 \%)$ & $8^{\text {th }}$ \\
\hline Far North & $18(90 \%)$ & $2(10 \%)$ & $20(100 \%)$ & $8^{\text {th }}$ \\
\hline
\end{tabular}

The good ranking of pupils from schools in the Centre and Littoral regions and the poor ranking of pupils from schools in the East and Far North regions can be accounted for in terms of availability of teachers, textbooks and to a minor extent, pupils' motivation to learn. But the real problem is that of the English syllabus in Francophone schools. It is evident that Francophone secondary school leavers cannot succeed in the TOEFL test because the teaching and the type of test they take do not prepare them for college level English. There is therefore a need to revamp the English course content and the system of assessment.

\section{Proposed syllabus and assessment method}

The analysis outlined above has revealed that the performance of Francophones who have been taught English as a secondary school subject for seven years is far below college level English. This is a problem that needs to be solved in the near future. Having observed this situation, many parents have opted to register their children in English-medium schools. By so doing, these children learn English in school and interact in French in the neighbourhood. As there are few English-medium schools in Francophone regions, only a tiny proportion of children can learn English effectively. If the government is serious about its French-English bilingualism policy and wants a large turnout, it would have to revise the English syllabus in Francophone school. Below is described a simple measure that is cost-effective.

The proposal reproduced here (Kouega 2005) assumes no substantial change in what has been going on before; in fact, the budget, classroom size, time allocation etc., are expected to remain the same. The two things that are to be changed are the course content and the teachers. Regarding the course content, the English language course in $6 \dot{e}$ should be a summary of the Grade 1 subjects in English-medium primary schools in Cameroon. The content of these subjects will not be new to the pupils, only the language i.e. English, will be new. Similarly, the 5 è course should be a summary of the Grades 2 and 3 subjects, which are not new to Francophone pupils. In the same light, the 4è course should be a summary of Grades 4 and 6, the $3 \dot{e}$ course a summary of Grade 6 subjects. Then the $2 n d e$ class will be devoted to the review of all of the primary level English and Francophone pupils will be encouraged to sit for the First school Leaving Certificate (FSLC). Obviously, a certain proportion of these pupils will pass this examination. Then lère pupils will be taught a summary of Form One subjects and those Francophone pupils who would have failed the FSLC will take it again. Finally, Terminale pupils will be taught a summary of Form II subjects and those who would have failed the FSLC the previous years would still take it. This is summarised in Table 17.

Table 18. A proposed pairing of L2 English curriculum and L3 English course syllabus for Francophones

\begin{tabular}{ll}
\hline $\begin{array}{l}\text { Curriculum for English-medium } \\
\text { schools (age of pupils: 5-11) }\end{array}$ & $\begin{array}{l}\text { Corresponding English course syllabus for } \\
\text { French-medium schools (age of pupils: 11-18) }\end{array}$ \\
\hline Grade One & Sixième class (Form One) \\
Grade Two and Three & Cinquième class (Form Two) \\
Grade Four and Five & Quatrième class (Form Three) \\
Grade Six & Troisième class (Form Four) \\
$\ldots \ldots . . . . . .$. & Seconde class (Form Five) \\
& NB: Review and preparation for the First School Leaving \\
& Certificate \\
Form One & Première class (Lower Sixth Form) \\
Form Two & Terminale class (Upper Sixth Form) \\
\hline
\end{tabular}

If this syllabus was followed, a reasonable proportion of Francophones will obtain the FSLC before they complete secondary education. In any case, even if they did not obtain this certificate their level would still be higher than it is at the moment. Regarding teaching, there is a need to train primary school teachers in great numbers so that there are 
enough for English-medium primary schools and French-medium secondary schools. As the training of primary teachers is cheaper than that of secondary teachers, no additional budget is needed. If this syllabus is adopted and the teaching is done effectively, then on completion of secondary education, Francophone pupils would perform very well, just like the 45 Form Two pupils whose performance in Structure was outlined in section 3 above. By so doing, the number of bilinguals in the country will triple in a relatively short time. That is if the government is serious about its French-English bilingualism policy.

\section{Conclusion}

This paper has examined the proficiency in English structure and written expression of Francophones when they leave secondary education. Informants who were drawn from schools in the ten regions of the country were subjected to a TOFEL-like structure test. The analysis revealed a number of interesting facts. First, these informants do not attain college level English when they graduate; in fact, Form 2 pupils in English-medium schools perform far better than them. Secondly, the English test they take in the Baccalauréat examination is a rag bag of exercises that does not follow any internationally recognised pattern. As a result, pupils who perform well in it tend to be lost when they have to take university courses in English. To overcome this problem, a bottom-up approach has been adopted by urban well-to-do parents, who register their children directly into English-medium schools. As a possible generalised solution, the English language syllabus needs to be changed and Francophone pupils should be taught the substance of English-medium primary school content, culminating in their taking the First School Leaving Certificate before or after completion of secondary education.

\section{References}

Eyenga, N. (2007). The testing of the speaking skill in the teaching of English as a foreign language in Cameroon secondary schools: A case study of GBPHS Yaounde. Unpublished DIPES II Dissertation. University of Yaounde I, ENS.

Hamers, D.J. and Blanc, M. H. A. (2000). Bilinguality and bilingualism. $2^{\text {nd }}$ edition. Cambridge: Cambridge University Press. http://dx.doi.org/10.1017/CBO9780511605796

Kouega, J. P. (2005). Promoting French-English individual bilingualism through education in Cameroon. Journal of Third World Studies. 22(1). pp.185-196.

Mbia Bekono., L. A. (2007). Language testing at the Baccalauréat A4 examination in Cameroon: An Evaluation of the reading and Essay Sections. Unpublished DEA Dissertation. University of Yaounde I.

MINEDUC. (2000). Final report on the reinforcement of bilingualism in the Cameroon education system. Yaounde.

Oller, J.W. (1984). Language testing: Where to from here?. In I. Feigenbaum (ed), English as a Second Language: Dimensions and Directions. Dallas: Summer Institute of Linguistics. pp. 15-46. http://dx.doi.org/10.1177/026553228400100207

Sokeng Piewo, Stephane Celeste (2011). The English language proficiency of Francophone secondary school leavers in Cameroon. Unpublished PhD Thesis, University of Yaounde I.

Wei, L. (2000). Dimensions of bilingualism. In L. Wei (ed), The Bilingualism Reader. London: Routledge. pp. 4-25. http://dx.doi.org/10.4324/9780203461341 


\section{APPENDIX 1}

\section{Sample Baccalauréat examination}

\section{MINESEC \\ OFFICE DU BACCALAURÉAT}

\section{BACCALAURÉAT A Session 2008}

\section{ANGLAIS}

\section{SECTION A: GRAMMAR (10 marks)}

1. Complete the following sentences by putting the items in the brackets in their correct forms. (5marks)

a) It's high time you. (to buy) your own calculator.

b) This book is worth (to read). You could borrow it for two weeks.

c) I wish I. (to come) with you to church yesterday.

d) I've spent... (much) time with you today than I usually do.

e) Your claim. (to be) examined right now by the director. Hold on for a minute.

2. Complete the sentences with the most appropriate words chosen from the brackets. (2.5 marks)

a) Bola is the silliest boy I've met. (always, never, ever)

b) He promised he would give me some money, but he hasn't............. (again, yet, still)

c) ............................difficult a test is, the better. (the more ,more, the most)

d) Never have I seen............................. clever woman. (so, that, such)

e) My father promised to send me some money as he......Mokolo. (reach, will each, went for)

3. Write the word in which the underlined letters are pronounced differently. (2.5 marks)

a) Word, corn, sword, sort, storm.

b) Blow, throw, grow, cow, snow.

c) Cloud, found, shout, group, thousand.

d) This, thought, these, through, themselves.

e) Niece, ties, field, thief, siege.

\section{SECTION B: VOCABULARY (10 marks)}

1. Complete the sentences with the most appropriate prepositions. (5marks)

a) Last year, jack was nearly convicted .............................murder. He was instead charged .................theft. The other cases..............him were dismissed.

b) The fruits I like most are those that I can transform.........................juice.

c) Poaching is a serious threat to animals in Cameroon; if nothing is done, some species will die.

1. Build compound words by matching the words in column A to those in column B, write in the spaces provided. (5marks)

\begin{tabular}{|c|c|c|}
\hline Column A & Column B & Your answer \\
\hline killer & Penalty & \\
\hline cross & handed & $\ldots$ \\
\hline love & disease & $\ldots$ \\
\hline family & discrimination & $\ldots$ \\
\hline gender & tongue & $\ldots \ldots$ \\
\hline mother & affair & $\ldots \ldots \ldots \ldots \ldots \ldots$ \\
\hline phone & examination & $\ldots \ldots \ldots \ldots \ldots \ldots$ \\
\hline growth & bill & \\
\hline death & rate & \\
\hline red & planning & 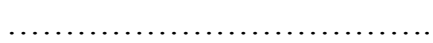 \\
\hline
\end{tabular}




\section{SECTION C: READING COMPREHENSION (10 marks)}

Read the following passage and answer the questions below it, using your own word as far as you can.

The tall, good-looking man with broad shoulders stood ramrod straight, proudly holding a small boy who sat relaxed and trusting in his father's arms. Both had warm brown eyes and white grins that arrested attention and sent a smile racing across my face. Kelly and little Kelly. These were the men in my life and I loved them deeply.

"Kelly here." The voice was etched in stress.

"Hi, honey, how's your day going? Day going?" I tried to sound relaxing.

"I've been in meeting all morning, and I have another one scheduled in just a few minutes, so I don't have long to talk. What's up".

"I just got back from an appointment with Dr. Ruth. I have some good news and some bad news". I hope humour would soften the unexpected.

"Give me the good news. I want to hear some good news today".

I laughed nervously. "You're not sterile".

Silence rose out of the phone toward me like thick smoke. Them I heard a taut exhale.

"Are you serious? You're kidding, right? This is probably the worst for us to have a new baby." The irritation in his voice was unmistakable. "I can't believe it. How could this have happened?"

Suddenly the smile I'd all morning vanished. Kelly lowered his voice, but there was no warmth in it.

"Pat, I don't want another baby. Listen, I'll support your decision either way, but I want you to know I don't want this baby."

My mind raced on. He decided just like that...: "I don’t want that baby." My knees folded beneath me and I slumped down on the couch. He said it so easily!

"I'll make an appointment with Dr. Poppy," I said in an irritated voice. Dr. Ruth being a lady, I couldn't see her this time.

"That's very good idea," he answered too quickly.

I felt betrayed, why did he react the way he did? Couldn't he at least be curious about my own dreams? Why didn't he ask, "How do you feel about this? What do you want, Pat?" My shock at his reaction puzzled me.

Two days later I drove downtown to Dr. Poppy gynecology clinic.

"Well, Pat, it's been a long time since I last saw you, Dr Poppy said cheerfully before closing the door behind him.

"So, Pat, how have you been?"

"Pretty good." I wanted to sound normal. "I'm here because I'm pregnant, and I'm concerned about possible complications, considering my age and medical background."

"I've managed patients with kidney transplants through successful pregnancies, and I feel confident we can do the same for you."

"Dr. Poppy, my marriage is pretty shaky. What about the possibility of an abortion?

"Pat! Pat! You know I'm a Christian and I can't do that. I advise you to keep your baby. Don't; we'll take good care of the pregnancy. Everything will be alright."

"Dr. Poppy, you don't understand. If I keep this baby, my marriage will crumble."

"Well, in this case, look for some other doctor; I'm afraid I can't help you."

(Patricia A. Bigliardi, Beyond the hidden pain of abortion, adapted) 


\section{Questions}

1) Who are the two main characters of the passage? (1 mark)

2) Was the news good or bad for Kelly? How do you know? (1 mark)

3) Why did Pat feel betrayed? (2 marks)

4) Who was going to make an appointment? What for? (2 marks)

5) What was Dr Poppy reaction? Why? (2 marks)

6) Do you think that Pat was right to make such a proposal to Dr Poppy? Justify your answer. (2 marks)

\section{SECTION D: ESSAY (10 marks)}

Write a composition of about 250-300 words on any ONE of the following topics:

1) Abortions: causes and drawbacks

2) Write a persuasive article for your school magazine in which you suggest changes in the education system of your country. Your school magazine is Students' voice and your name is NGONGUI Jose. Your address is P.O Box 200, Ndelele

3) A friend of yours is about to commit suicide. You try to dissuade him or her. Tell the story. 


\section{APPENDIX 2}

\section{Structure and Written Expression}

40 Questions

25 Minutes

This section is designed to measure your ability to recognize language that is appropriate for standard written English. There are two types of questions in this section, with special directions for each type.

Directions: Questions 1-15 are incomplete sentences. Beneath each sentence you will see four words or phrases, marked (A), (B), (C), and (D). Choose the one word or phrase that best completes the sentence.

1. To answer accurately is more important than
(A) a quick finish
(B) to finish quickly
(C) finishing quickly
(D) you finish quickly

2. Lecturers expect.......... when it is necessary to cancel an appointment.
(A) you to call
(B) that you would call them
(C) your calling them
(D) that you are calling them

3. The policeman made us
(A) showing
(B) show
(C) showed
(D) to show

4. The heir ..........his father's business.
(A) took
(B) took over
(C)taking
(D) took on

5. Poverty is often accompanied our identification in order to be admitted in the conference hall. appetite.
(A) by
(B) with
(C) of
(D) in

6. The greater the demand,........................the price.
(A) the high
(B) the higher
(C) high
(D) higher

7. Together let's fight AIDS.
(A) for
(B) against
(C) any
(D) again 
8. Another sub-theme discussed last year to do with management.
(A) was
(B) is
(C) have
(D) had

9. The 2008 Africa Nation's cup in Ghana.
(A) is held
(B) was held
(C) was hold
(D) has been hold
10. Pregnant women. as carbohydrates.
(A) shall be told
(B) should be told
(C) was told
(D) is told what vitamins can do to the body, the importance of protein as well

11. Beauty .can be a passport to success.
(A) only
(B) always
(C) alone
(D) although

12. It is never to take the AIDS test.
(A) early
(B) earlier
(C) too early
(D) too earlier

13. Would you like to me?
(A) marrying
(B) marry
(C) get marry
(D) married

14. Many young Africans
(A) do
(B) do not
(C) did not
(D) will not

15. AIDS thousands of people every year.
(A) killed
(B) kills
(C) has killed
(D) have killed

\section{WRITTEN EXPRESSION}

Directions: In questions 16-40, each sentence has four underlined words or phrases. The four underlined parts of the sentence are marked (A), (B), (C), and (D). Circle the one underlined word or phrase that must be changed in order for the sentence to be correct. 
16. The project $\underline{\boldsymbol{w h} \boldsymbol{o}}$ will be managed in segments is expected to cost CFA $1,745,200$.
(A)
(B)
(C)
(D)

17. The main characters are clearly delineated between the first chapter of the book.
(A)
(B)
(C)
(D)

18. Although some people campaign $\underline{\boldsymbol{t o}}$ the right to homosexuality, it is still illegal in most countries.
(A)
(B)
(C) (D)

19. Every day, those are reports of refugees dying of famine in sub Africa.
(A)
(B)
(C)
(D)

20. $\underline{\text { Swim }}$ in a river can be very dangerous if you do not know how to swim.
(A)
(B)
(C)
(D)

21. Mary rushed to the kitchen, unfortunately it was too late, there was nothing else she could do, the dog $\underline{\text { was }}$

(A)

(B)

(C)

(D)

already eaten the food.

22. Because the arrival of new communication technologies, it is important for children nowadays to have a

(A)

(B)

(C)

(D)

computer at home.

23. You can have more job opportunity if you are bilingual.
(A) (B)
(C)
(D)

24. If you export informations from a computer, you copy large amount of it either to different parts as the
(A)
(B)

computer's storage space or to another formal of storage such as a floppy disk, so it can be used for a different

(C)

(D)

purpose.

25. Political leaders often flatter peoples because they want to be elected.
(A)
(B) $\quad(\mathrm{C})$
(D)

26. Last year, it rains so much that the government had to provide financial aid to flood victims.

(A)

(B)

(C)

(D)

27. A World Health Organisation's report say malaria kills more people in Africa than AIDS.
(A)
(B) $\quad(\mathrm{C})$
(D)

28. The World Trade Centre's bomb explosion has been one of the worst acts of terrorism that America has
(A)
(B)
(C)

experience in recent years.

(D)

29. During the $1994 \underline{\text { civil }}$ war in Rwanda many people were killed and many others injured.
(A)
(B)
(C)
(D)

30. Love is such a beautiful thing when you love each other for passion.
(A)
(B)
(C) (D)

31. I can remember the first time I go hunting, it was an exciting sensation.
(A)
(B)
(C)
(D)

32. It is a long time I $\underline{\boldsymbol{h a s}}$ not received any letter; I only receive and send electronic mails.
(A)
(B)
(C)
(D) 
33. If you need more informations, please contact our office.
(A)
(B)
(C)
(D)

34. Nelson Mandela is famous for his fight for apartheid.
(A) (B)
(C) (D)

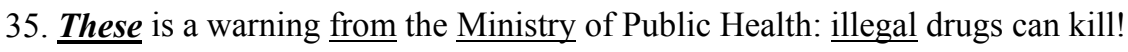
(A)
(B)
(C)
(D)

36. If you want to know if you are infected or not, you needed to do an AIDS's screening test.
(A)
(B)
(C)
(D)

37. The policeman suggested that we go to the police station if we had something to add.
(A)
(B)
(C) (D)

38. The more important or powerful a person $\underline{\text { is }}$, the more difficult it is for $\underline{\text { them }}$ when he loses his importance or

(B)

(C)

(D)

power.

39. Parents should try to create a stable home environment for them children to grow up in.

(A)

(B)

(C)

(D)

40. More and more smoking is regarded as $\underline{\boldsymbol{a}}$ anti-social habit.
(A)
(B)
(C)
(D) 